\title{
Long-range effects of colchicine sensitivity on meiosis in Lolium multiflorum L. (Italian ryegrass)
}

\author{
LUTFUL HASSAN $\dagger \&$ R. NEIL JONES* \\ Institute of Biological Sciences, University of Wales Aberystwyth, Aberystwyth SY23 3DD, U.K.
}

\begin{abstract}
A 3-h treatment period with 0.2 per cent colchicine on 1-week-old seedlings of inbred lines of Italian ryegrass (Lolium multiflorum L.) has long-range effects on chromosome behaviour at meiosis. There is a reduction of mean pollen mother cell chiasma frequency, an increase in univalents and in cell and bivalent variances, and also changes in the pattern of chiasma distribution within bivalents. The effects are seen in the generation in which the treatment is given, and in the following sexual generation.
\end{abstract}

Keywords: chiasma distribution, colchicine, Lolium multiflorum, meiosis.

\section{Introduction}

There have been many experiments performed in which colchicine has been used as an agent to investigate the mechanism and time of meiotic chromosome pairing. The drug has usually been injected into the inflorescences of plants, or the gonads of animals, at the time of pairing, or sometimes earlier. Analysis at metaphase I has then been used to determine the windows of sensitivity, and to relate the effects observed to the underlying processes of pairing and crossing-over.

All authors agree that colchicine reduces chiasma frequency, and that it disturbs spindle structure at meiosis I and II. Multivalents are frequently seen in diploids. Disturbances at premeiotic association have been identified by Driscoll et al. (1967), Driscoll \& Darvey (1970), Dover \& Riley (1973), Avivi (1976), Bennett et al. (1979) and Puertas et al. (1984). Interference with ongoing synapsis during early prophase has been reported by Levan (1939), Barber (1942), Shepard et al. (1974), Thomas \& Kaltsikes (1977), de la Peña \& Puertas (1978), de la Peña et al. (1979) and Loidl (1988, 1989). Lengthening of leptotene, and modification of pairing conditions, has been described by Barber (1942) and Loidl $(1988,1989)$. The literature on this subject, in the context of a general review

${ }^{*}$ Correspondence.

†Present address: Department of Genetics and Plant Breeding, Bangladesh Agricultural University, Mynensingh-2202, Bangladesh. on chromosome pairing, has recently been discussed in detail by Loidl (1990).

The application of colchicine has generally been at the time when the pairing and exchange processes are deemed to occur, namely early prophase I, or premeiotically where studies have been aimed at investigating premeiotic alignment. In only one case has the application of colchicine been made early on in development, and this was done in Antirrhinum majus by Sparrow (1942), who treated young cuttings some 6-15 weeks before anthers were fixed for meiotic analysis. Comparisons of colchicine-treated diploids with water-treated controls showed a significant increase in univalent frequency, and in the majority of plants examined meiosis occurred during the eighth week or longer after application of the treatment. This long-term effect in Antirrhinum appears to be unique among investigations made to date. Finch \& Bennett (1979) compared chiasma frequencies in newly synthesized dihaploids with those made two generations earlier, and found a small reduction in pollen mother cell (PMC) chiasma frequency in the newly treated material, but in this case the controls were also derived by colchicine doubling.

In Lolium multiflorum we have used colchicine on newly germinated seeds, and then studied the effects of colchicine on diploid meiocytes both in the treatment generation (CT0) and also in the next sexual generation (CT1). The comparisons were therefore between normal diploids $(2 \mathrm{x})$ and their treated isogenic lines $(\mathrm{C} 2 \mathrm{x})$. The experiments were originally designed for 
the study of agronomic characters, but an analysis of meiosis was included out of curiosity. The results indicate long-range colchicine effects on chiasma frequency and distribution which are heritable through at least one sexual generation.

\section{Material and methods}

The material consists of inbred lines of Italian ryegrass (Lolium multiflorum L.). This is the same material as that used in earlier experiments on colchicine-induced variation in agronomic (Hassan et al., 1989) and cell characters (Hassan et al., 1991).

The lines originate from experimental material developed by Professor G. Kobabe at Göttingen, and these lines are now maintained and supplied by $\mathrm{Dr}$ U. K. Posselt at Hohenheim. It can be assumed that we are dealing with pure breeding homozygous lines.

Seeds from 10 lines were 'sown' on moist filter paper in Petri dishes in October 1986. The dishes were placed in a refrigerator for 1 week at $4^{\circ} \mathrm{C}$ to aid germination, and were then kept at room temperature. When the seedlings had grown to $2-3 \mathrm{~cm}$ a sample was treated by total immersion in 0.2 per cent aqueous colchicine for $3 \mathrm{~h}$ at room temperature $\left(\sim 18^{\circ} \mathrm{C}\right)$, and another sample was treated with water as a control. After washing and recovery from the treatment the two groups of seedlings were planted in John Innes compost and grown on in plastic multitrays in a heated glasshouse. The survival rate among the colchicinetreated sample was of the order of 65 per cent. At the age of 7 weeks the plants were transferred to 5 -in pots in John Innes compost and were grown on to flowering in an unheated glasshouse.

Flowering occurred in May-June 1987 and then the spikes were fixed in Carnoy's fluid for analysis of meiosis. Colchicine-treated lines were mixoploids, but only the diploid spikes were used in this experiment. Several spikes were fixed from each of five plants in each line/treatment. The remaining spikes were bagged at anthesis to give selfed seed for the next generation, where diploids were identified after chromosome counting of seedlings, and their spikes likewise fixed for meiosis in the following season. Squashes of PMCs for meiotic analysis were made in acetocarmine.

Chiasma frequency and distribution patterns at metaphase I (MI) were recorded for a sample of 20 PMCs for each of five plants in each line. Chiasma positions within bivalents were classified subjectively into three categories: (i) those at the ends of chromosome arms, with no side arms visible beyond the point of exchange, were recorded as distal; (ii) those in the regions intermediate between the centromere and the end of the arms, such that side arms were equal to or less than the length of arm between the centromere and the chiasma, were recorded as interstitial; and (iii) those adjacent to the centromere, with side arms greater in length than the distance between centromere and chiasma, as proximal (based on Karp \& Jones, 1983).

The nomenclature is that untreated diploid controls are known as $2 x$ plants, and colchicine-treated diploids as $\mathrm{C} 2 \mathrm{x}$. Plants of the generation in which treatment was applied are designated CT0 $(2 \mathrm{x}$ or $\mathrm{C} 2 \mathrm{x})$, and those from the next sexual generation without any further treatment as the CT1 $(2 \mathrm{x}$ or $\mathrm{C} 2 \mathrm{x})$.

\section{Results}

\section{CTO generation}

The data for mean PMC chiasma frequencies per line, in both the $2 \mathrm{x}$ and $\mathrm{C} 2 \mathrm{x}$ treatments, are summarized in Table 1. The table also gives the levels of significance for treatment differences from a one-way analysis of variance. Overall the $\mathrm{C} 2 \mathrm{x}$ have a lower number of chiasmata than the $2 \mathrm{x}$, of the order of 1.2 chiasmata per cell $(P<0.001)$, and the reduction affects all 10 lines. In only two lines ( $\mathrm{Lm} \mathrm{126,} \mathrm{Lm} \mathrm{131)} \mathrm{is} \mathrm{the} \mathrm{differ-}$ ence non-significant, and in seven out of the 10 it is highly significant $(P<0.001)$. The effect is markedly consistent and unidirectional, and has occurred some 30 weeks after the time at which the treatment was applied. In terms of univalents (Table 1, Fig. 1) the C2x have an overall mean of 0.93 per cell, compared with 0.18 for the $2 \mathrm{x}(P<0.001)$, and there are significant differences between treatments in all 10 of the lines.

Cell variances indicate the variation in chiasma distribution between PMCs within plants, and are calculated as the variance of the 20 individual PMC scores per plant. These data are also listed in Table 1, together with their analysis. Overall the cell variance is greater for the $\mathrm{C} 2 \mathrm{x}$ than for the $2 \mathrm{x}$ treatment $(P<0.001)$, and there are significant increases in five out of the 10 lines. In the five lines where the difference is non-significant the $\mathrm{C} 2 \mathrm{x}$ are all higher than the $2 \mathrm{x}$. There is no correlation of the variances with the means, and the treatment has altered the pattern of chiasma distribution between PMCs, making it less regular.

Bivalent variances are calculated from the seven scores for chiasmata per bivalent within PMCs, and then averaged over the 20 PMCs per plant. They reflect chiasma distribution between bivalents within cells. The data are listed in Table 1, and they show an increase in variance due to the colchicine treatment effect $(P<0.001$, overall $)$, and the increase affects all lines except $\mathrm{Lm} 131$. Bivalent variances were also calculated for the PMC chiasma frequency classes of 10 , 11,12 and 13, which are common to lines $\mathrm{Lm} \mathrm{41,} \mathrm{Lm}$ 122 and $\mathrm{Lm}$ 125. Within this selected and identical 
Table 1 Summary of data and analysis for chiasma frequency and distribution in the $2 x$ and $C 2 x$ treatments of 10 inbred lines of Lolium multiflorum in the CT0 generation. The mean values in the table are each based on five plants and a sample of 20 PMCs per plant

\begin{tabular}{|c|c|c|c|c|c|c|c|c|c|c|c|c|}
\hline \multirow[b]{2}{*}{ Line } & \multicolumn{3}{|c|}{ PMC chiasma frequency } & \multicolumn{3}{|c|}{ Cell variance } & \multicolumn{3}{|c|}{ Bivalent variance } & \multicolumn{3}{|c|}{ Univalents } \\
\hline & $2 x$ & $\mathrm{C} 2 \mathrm{x}$ & $P$ & $2 x$ & $C 2 x$ & $P$ & $2 x$ & $C 2 x$ & $P$ & $2 x$ & $C 2 x$ & $P$ \\
\hline 41 & 12.67 & 10.44 & $* * *$ & 0.736 & 2.312 & $*$ & 0.2095 & 0.3295 & $* * *$ & 0.00 & 0.54 & $* * *$ \\
\hline 48 & 13.96 & 12.48 & $* * *$ & 1.877 & 1.942 & NS & 0.4419 & 0.4743 & NS & 0.06 & 0.76 & $* * *$ \\
\hline 62 & 11.21 & 10.22 & $* * *$ & 1.152 & 3.137 & $* * *$ & 0.3190 & 0.4295 & $* * *$ & 0.22 & 1.14 & $* * *$ \\
\hline 74 & 12.32 & 10.93 & $* *$ & 1.458 & 2.171 & NS & 0.1995 & 0.4009 & $* * *$ & 0.12 & 1.02 & ** \\
\hline 87 & 12.69 & 12.21 & $* * *$ & 1.076 & 1.670 & NS & 0.2362 & 0.2705 & $*$ & 0.26 & 0.48 & ** \\
\hline 119 & 14.89 & 13.75 & $* * *$ & 1.774 & 2.893 & * & 0.3442 & 0.4143 & $* *$ & 0.00 & 0.58 & $* * *$ \\
\hline 122 & 12.71 & 10.14 & $* * *$ & 1.013 & 2.959 & $* *$ & 0.2209 & 0.4766 & $* * *$ & 0.14 & 1.54 & $* * *$ \\
\hline 125 & 12.13 & 10.85 & $* * *$ & 0.721 & 0.922 & * & 0.2947 & 0.4209 & $* * *$ & 0.10 & 0.92 & $* * *$ \\
\hline 126 & 12.30 & 12.16 & NS & 1.748 & 2.356 & NS & 0.4152 & 0.4190 & NS & 0.34 & 0.64 & * \\
\hline 131 & 11.35 & 11.09 & NS & 2.012 & 2.026 & NS & 0.5447 & 0.5100 & NS & 0.52 & 1.64 & $* * *$ \\
\hline Mean & 12.62 & 11.43 & $* * *$ & 1.357 & 2.239 & $* * *$ & 0.3226 & 0.4145 & $* * *$ & 0.18 & 0.93 & $* * *$ \\
\hline
\end{tabular}

$* P \leqslant 0.05,{ }^{* *} P \leqslant 0.01,{ }^{* * *} P \leqslant 0.001, \mathrm{NS}=$ non-significant.

Fig. 1 Mean univalents per cell for colchicine-treated $\mathrm{C} 2 \mathrm{x}$ and for control $2 \mathrm{x}$ plants of inbred lines of Lolium multiflorum in CTO treatment generation.

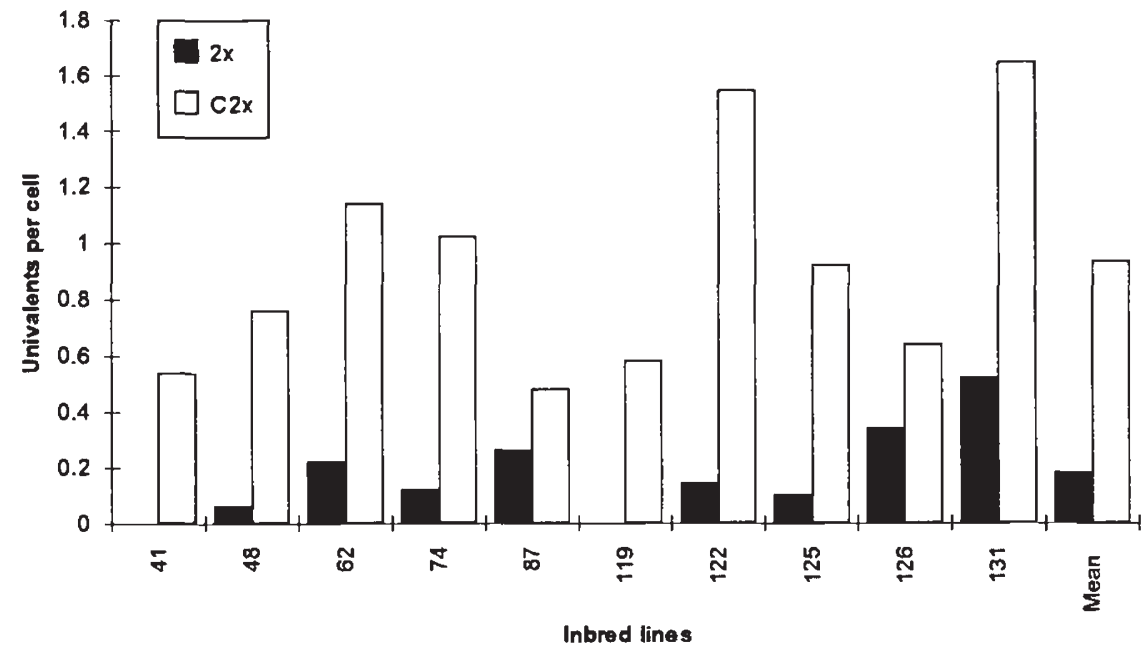

chiasma frequency class range the bivalent variances are again shown to be higher in the $\mathrm{C} 2 \mathrm{x}$ than the $2 \mathrm{x}$ treatment $(P<0.001$ in all three lines $)$, confirming that the difference is independent of variation in mean PMC chiasma frequency between treatments.

The data for variation in chiasma distribution within bivalents, arbitrarily classified into proximal, interstitial and distal positions, are summarized as means per plant in Table 2. Overall the $\mathrm{C} 2 \mathrm{x}$ show a significant decrease $(P<0.001)$ in proximal chiasmata compared with the $2 x, 2.22$ and 5.00 respectively, and the trend is consistent over all lines. Interstitial chiasmata follow a similar pattern of reduction in the $\mathrm{C} 2 \mathrm{x}$ treatment, and the effect is again seen over all lines and is significant in eight out of the 10 lines. Distal chiasmata show the opposite effect, with an increased overall frequency in the $\mathrm{C} 2 \mathrm{x}(P<0.001)$, and significant effects in eight of the 10 lines. The colchicine treatment evidently leads to a redistribution of chiasmata within bivalents, and moves them away from proximal and interstitial regions towards the ends of the chromosome arms.

\section{CT1 generation}

In the CT0 generation the colchicine effects on meiosis were being revealed some 30 weeks after the time at 
Table 2 Summary of data for distribution pattern of chiasmata within bivalents in the $2 \mathrm{x}$ and $\mathrm{C} 2 \mathrm{x}$ treatments of 10 inbred lines of Lolium multiflorum in the CT0 generation. Mean values in the table are based on five plants in each line and a sample of 20 PMCs per plant. Percentage values were transformed to angles for the analysis

\begin{tabular}{|c|c|c|c|c|c|c|c|c|c|}
\hline \multirow[b]{2}{*}{ Line } & \multicolumn{3}{|c|}{ Proximal (\%) } & \multicolumn{3}{|c|}{ Interstitial $(\%)$} & \multicolumn{3}{|c|}{ Distal (\%) } \\
\hline & $2 x$ & $\mathrm{C} 2 \mathrm{x}$ & $P$ & $2 x$ & $C 2 x$ & $P$ & $2 x$ & $\mathrm{C} 2 \mathrm{x}$ & $P$ \\
\hline 41 & 2.92 & 0.19 & **** & 8.21 & 6.32 & $* *$ & 88.87 & 93.68 & $* * *$ \\
\hline 48 & 12.31 & 5.01 & $* * *$ & 18.33 & 16.86 & NS & 69.35 & 78.13 & * \\
\hline 62 & 0.80 & 1.18 & NS & 28.01 & 10.19 & $* * *$ & 71.19 & 88.63 & $* * *$ \\
\hline 74 & 0.00 & 0.00 & - & 11.13 & 8.10 & NS & 88.87 & 91.90 & NS \\
\hline 87 & 1.26 & 0.49 & $* * *$ & 11.26 & 6.48 & $* * *$ & 87.42 & 93.03 & $* * *$ \\
\hline 119 & 15.71 & 7.93 & $* * *$ & 25.72 & 18.26 & $* * *$ & 58.56 & 73.81 & $* * *$ \\
\hline 122 & 1.10 & 0.00 & $* * *$ & 14.88 & 9.77 & $* * *$ & 84.02 & 90.23 & $* * *$ \\
\hline 125 & 2.63 & 1.20 & $* * *$ & 25.31 & 9.77 & $* * *$ & 72.06 & 87.03 & $* * *$ \\
\hline 126 & 6.26 & 6.16 & NS & 12.51 & 10.94 & * & 81.23 & 82.89 & NS \\
\hline 131 & 6.96 & 0.00 & $* * *$ & 25.12 & 9.38 & $* * *$ & 67.90 & 90.60 & $* * *$ \\
\hline Mean & 5.00 & 2.22 & $* * *$ & 18.05 & 10.61 & $* * *$ & 76.95 & 87.00 & $* * *$ \\
\hline
\end{tabular}

${ }^{*} P \leqslant 0.05,{ }^{* *} P \leqslant 0.01,{ }^{* * * *} P \leqslant 0.001, \mathrm{NS}=$ non-significant.

Table 3 Summary of data and analysis of chiasma frequency and distribution in the $2 x$ and C2x treatments of 10 inbred lines of Lolium multiflorum in the CT1 generation. The mean values in the table are each based on five plants and a sample of 20 PMCs per plant

\begin{tabular}{|c|c|c|c|c|c|c|c|c|c|c|c|c|}
\hline \multirow[b]{2}{*}{ Line } & \multicolumn{3}{|c|}{ PMC chiasma frequency } & \multicolumn{3}{|c|}{ Cell variance } & \multicolumn{3}{|c|}{ Bivalent variance } & \multicolumn{3}{|c|}{ Univalents } \\
\hline & $2 \mathrm{x}$ & $\mathrm{C} 2 \mathrm{x}$ & $P$ & $2 \mathrm{x}$ & $\mathrm{C} 2 \mathrm{x}$ & $P$ & $2 \mathrm{x}$ & $\mathrm{C} 2 \mathrm{x}$ & $P$ & $2 x$ & $\mathrm{C} 2 \mathrm{x}$ & $P$ \\
\hline 41 & 12.67 & 10.40 & $* * *$ & 0.725 & 2.476 & $*$ & 0.2127 & 0.3324 & $* * *$ & 0.00 & 0.58 & $* * *$ \\
\hline 48 & 13.98 & 12.44 & $* * *$ & 1.769 & 1.978 & NS & 0.4395 & 0.4749 & NS & 0.08 & 0.86 & $* * *$ \\
\hline 62 & 11.09 & 10.18 & $* * *$ & 1.093 & 3.257 & $* * *$ & 0.3277 & 0.4436 & $* * *$ & 0.24 & 1.28 & $* * *$ \\
\hline 74 & 12.35 & 10.96 & $* *$ & 1.497 & 2.260 & NS & 0.2001 & 0.4311 & $* * *$ & 0.14 & 1.12 & $* *$ \\
\hline 87 & 12.70 & 12.22 & $* * *$ & 1.165 & 1.142 & NS & 0.2307 & 0.2354 & NS & 0.26 & 0.40 & NS \\
\hline 119 & 14.87 & 13.54 & $* * *$ & 1.279 & 2.522 & * & 0.3519 & 0.4124 & * & 0.00 & 0.58 & $* * *$ \\
\hline 122 & 12.70 & 10.07 & $* * *$ & 1.121 & 2.215 & $* *$ & 0.2110 & 0.4566 & $* * *$ & 0.12 & 1.32 & $* * *$ \\
\hline 125 & 12.08 & 10.77 & $* * *$ & 0.749 & 1.039 & * & 0.3022 & 0.4224 & $* * *$ & 0.14 & 0.92 & $* * *$ \\
\hline 126 & 12.41 & 12.12 & $* * *$ & 1.774 & 2.412 & NS & 0.4187 & 0.4184 & NS & 0.32 & 0.60 & * \\
\hline 131 & 11.31 & 11.09 & NS & 2.040 & 1.842 & NS & 0.5470 & 0.5121 & NS & 0.62 & 1.52 & $* * *$ \\
\hline Mean & 12.62 & 11.38 & $* * *$ & 1.321 & 2.116 & $* * * *$ & 0.3241 & 0.4139 & $* * * *$ & 0.19 & 0.92 & $* * *$ \\
\hline
\end{tabular}

${ }^{*} P \leqslant 0.05,{ }^{* *} P \leqslant 0.01,{ }^{* * *} P \leqslant 0.001, \mathrm{NS}=$ non-significant.

which the burst of treatment was given to the seedlings, and it was clearly of interest and importance to see whether or not the effects would carry over through a sexual generation produced by selfing. The results indicate that this is the case. The mean PMC chiasma frequency per plant datum are summarized, together with the analysis, in Table 3. As the data show, the pattern is the same as for the CTO, and the mean values for the treatments overall are also virtually identical for the CT1 and the CT0. The generations were, however, grown in different years, and the analysis was confined to the meaningful effects of a carry-over of differences between treatments within generations rather than to a statistical comparison between the generations themselves. Data on univalents are also given in Table 3, as well as in the histograms in Fig. 2.

Cell variances and bivalent variances (Table 3) follow similar and consistent patterns, and have similar values to those of the CT0. 
Fig. 2 Mean univalents per cell for colchicine-treated $\mathrm{C} 2 \mathrm{x}$ and for control $2 \mathrm{x}$ plants of inbred lines of Lolium multiflorum in the $\mathrm{CT} 1$ generation.

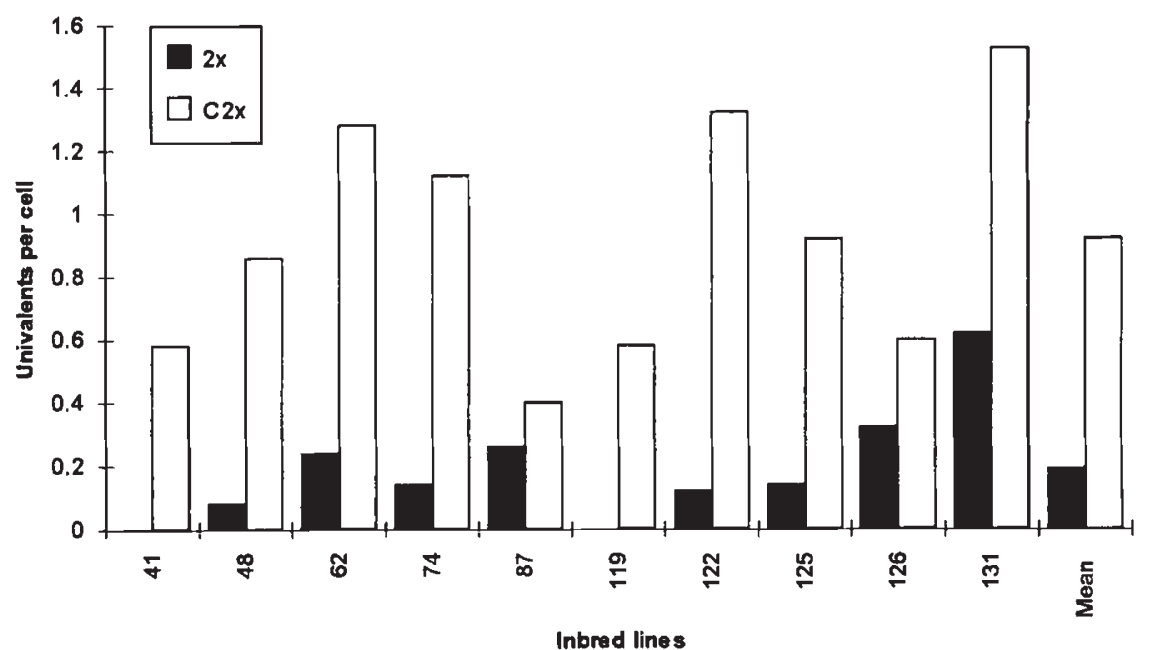

Table 4 Summary of data and analysis for patterns of chiasmata distribution within bivalents in the $2 \mathrm{x}$ and $\mathrm{C} 2 \mathrm{x}$ treatments of 10 inbred lines of Lolium multiflorum in the CT1 generation. Mean values in the table are based on five plants in each line and a sample of 20 PMCs per plant. Percentage values were transformed to angles for the analysis

\begin{tabular}{|c|c|c|c|c|c|c|c|c|c|}
\hline \multirow[b]{2}{*}{ Line } & \multicolumn{3}{|c|}{ Proximal (\%) } & \multicolumn{3}{|c|}{ Interstitial (\%) } & \multicolumn{3}{|c|}{ Distal (\%) } \\
\hline & $2 \mathrm{x}$ & $\mathrm{C} 2 \mathrm{x}$ & $P$ & $2 \mathrm{x}$ & $\mathrm{C} 2 \mathrm{x}$ & $P$ & $2 \mathrm{x}$ & $\mathrm{C} 2 \mathrm{x}$ & $P$ \\
\hline 41 & 2.72 & 0.0 & . & 8 & 0.00 & $* *$ & 89.19 & 100.00 & $* * *$ \\
\hline 48 & 11.94 & & $* * *$ & 18.15 & 17.47 & $\mathrm{~N}$ & .91 & 68 & * \\
\hline 62 & 0.72 & 1.28 & $*$ & 28.58 & 10.42 & $* * *$ & 0.70 & 8.30 & $* * *$ \\
\hline 74 & 0.00 & 0.00 & - & 10.98 & 5.42 & $* *$ & 39.02 & 94.58 & $* *$ \\
\hline 87 & 1.25 & 0.53 & $* *$ & 11.10 & 6.57 & $* * *$ & 87.65 & 92.91 & $* * *$ \\
\hline 119 & 14.12 & 7.75 & $* * *$ & 22.53 & 15.22 & $* * *$ & 63.35 & 77.03 & $* * *$ \\
\hline 122 & 0.86 & 0.0 & $* * *$ & 11.18 & 7.65 & $* * *$ & 87.95 & 92.35 & $* * *$ \\
\hline 125 & 2.63 & 1.2 & $* *$ & 25.41 & 9.95 & $* * *$ & 71.96 & 88.80 & $* * *$ \\
\hline 126 & 6.40 & 5.9 & NS & 12.48 & 10.88 & $*$ & 81.13 & 83.20 & * \\
\hline 131 & 6.99 & 0.00 & $* * *$ & 25.16 & 9.32 & $* * *$ & 67.84 & 90.68 & $* *$ \\
\hline Mean & 4.76 & 2.26 & $* * *$ & 17.37 & 9.29 & $* * *$ & 77.87 & 88.45 & $* * *$ \\
\hline
\end{tabular}

${ }^{*} P \leqslant 0.05,{ }^{* *} P \leqslant 0.01,{ }^{* * *} P \leqslant 0.001, \mathrm{NS}=$ non-significant.
Chiasma distributions within bivalents (Table 4) likewise show treatment differences of the same order of magnitude as those found in the CT0.

It is clear that in terms of both chiasma frequency and chiasma distribution, the colchicine effects observable in the CTO generation are transmitted undiminished through a sexual generation, and that they are heritable.

\section{Discussion}

The work reported here originated as an experiment to determine the true effects of chromosome doubling in perennial ryegrasses (Lolium perenne), using inbred lines. Colchicine was used as the doubling agent, and as controls for each line the colchicine-treated but undoubled plant parts $(\mathrm{C} 2 \mathrm{x})$ were kept, as well as the untreated diploids $(2 \mathrm{x})$. It was discovered, from comparisons of the $C 2 x$ and $2 x$ material, that the treatment agent itself had marked effects upon many aspects of plant development, and this novel finding was then pursued in both Lolium perenne and $L$. multiflorum in place of the original objective. The effects of colchicine on the agronomic and cell characters of ryegrass have been reported and discussed (Hague \& Jones, 1987; Francis et al., 1990; Hassan et 
al., 1989, 1991), and suffice it to say here that colchicine hastens development, results in more tillers and increases fresh weight, mesophyll cell size and chloroplast numbers. The changes are heritable and repeatable, but the basis of the effect has not been elucidated. There do not appear to be any maternal effects, although it has been difficult to validate this conclusion due to the strong self-incompatibility system of the ryegrasses.

The work on meiosis in Lolium multiflorum was therefore undertaken out of curiosity, against the background of these other well-established findings. We also had in mind the long-standing interest that many workers have had in using colchicine as an experimental tool to study chromosome pairing and recombination processes, although no particular hypothesis was being tested in this instance. As described, strong effects were found on chiasma frequency and distribution at MI of meiosis. The effects were found at flowering time, some 30 weeks on from the time of the 3 -h treatment period as seedlings, and they were also carried over undiminished into the next sexual generation without any further treatment.

The only other similar case of such long-range effects that we are aware of is that of Sparrow (1942). Sparrow treated cuttings of Antirrhinum with 0.1, 0.15 and 0.25 per cent aqueous colchicine for periods ranging from 7 to $42 \mathrm{~h}$ some 6-15 weeks before meiosis, and then found a reduction in the number of univalents at MI. He concluded that the colchicine must have reduced crossing-over in at least one pair of chromosomes, possibly by altering chromosome structure or by persisting in the plant in its original or in some derived form. Surprisingly there have not been any other investigations, to our knowledge, either to confirm or to extend the Antirrhinum work. The results reported here were also made without knowledge of Sparrow's data, and they suggest that long-term persistence of colchicine, or some derivative of it, is not a likely explanation of the effects. It is difficult to argue that chemical substances can be sexually transmitted without any dilution of effect, but more logical to suggest some induced developmental modification to plant development.

The meiotic effects described here in L. multiflorum do not stand alone as being due to colchicine. As mentioned above, they are but one character out of many that are developmentally modified in both perennial and Italian ryegrasses. There are also independent results for similar effects on agronomic characters, namely in Sorghum (see Erichsen et al., 1962; Hague \& Jones, 1987, for references) and for changes in chloroplast numbers in Sphagnum (G. Duckett, personal communication). The implication from the ryegrass work is that some common structural feature of the cells - controlling cell division, cell size, chloroplast distribution and chromosome behaviour - is heritability affected. A possible candidate structure, whose sensitivity to colchicine is well documented, is the cytoskeleton and its microtubular components which are vital structures influencing chromosome behaviour. It is not clear whether the effects of colchicine on fibrillar material seen in the nuclei of wheat meiocytes (by Bennett \& Smith, 1979) has any relation with the present observations.

There are numerous reports of colchicine effects resulting from its application at various defined stages of meiosis, or premeiotically, in which authors have attempted to unravel the intricacies of pairing and recombination in both plants and animals by disrupting the normal course of events (see Introduction for references). The literature on this topic, and the broader area of the cytological view of the initiation of meiotic pairing, has recently been covered in depth by Loidl (1990), and the reader is referred to this review for the relevant literature and a synthesis of it. One point that Loidl makes is that all interpretations of stage-specific meiotic effects of colchicine are confounded with possible effects that the substance might have on altering the duration of meiotic stages. The suggestion is pertinent here since, although cell cycles have not been studied, we do know that one of the effects of colchicine in ryegrass is to shorten the time from seed germination to anthesis, indicating a faster rate of development. This hastening of development could include meiosis itself, and this effect could present the nucleus with a reduced window for its meiotic processes. The other effect that some authors have alluded to is the effect of colchicine on chromosome disposition (see Loidl for context and review), and this would fit with the present observations, even to the extent that disposition can be influenced in seedlings, and then affected right through to meiosis and on into the following generation. It is unfortunate that, in the many studies made to date, the workers concerned have not thought to use some of the colchicine-treated flowers for seed production, and for studies on the following generation.

\section{References}

AVIVI, L. 1976, Colchicine induced bivalent pairing of tetraploid microsporocytes in Triticum longissimum and $T$. speltoides. Can. J. Genet. Cytol., 18, 731-738.

BARBER, H. N. 1942. The experimental control of chromosome pairing in Fritillaria. J. Genet., 43, 359-374.

BENNETT, M. D. AND SMITH, J. B. 1979. The effect of colchicine on fibrillar material in wheat meiocytes. J. Cell. Sci., $\mathbf{3 8}$, $33-47$. 
BENNETT, M. D., TOLEDO, L. A. AND STERN, H. 1979. The effect of colchicine on meiosis in Lilium speciosum cv. 'Rosemede'. Chromosoma, 72, 175-189.

DE LA PEÑA, A. AND PUERTAS, M. J. 1978. Colchicine induced asynapsis and $\mathrm{C}$-meiosis in pollen mother cells of cultivated anthers of rye. Chromosoma, 68, 261-267.

DE LA PEÑA, A., PUERTAS, M. J.. CERMEÑO, M. C. AND GIRALDEZ, R. 1979. Evidence of crossing-over inhibition in rye anthers cultured in colchicine. Chromosoma, 72, 151-155.

DOVER, G. A. AND RILEY, R. 1973. The effect of spindle inhibitors applied before meiosis on meiotic chromosome pairing. J. Cell. Sci., 12, 143-161.

DRISCOLL, C. J. AND DARVEY, N. L. 1970. Chromosome pairing: effect of colchicine on an isochromosome. Science, $\mathbf{1 6 9}$, 290-291.

DRISCOLL, C. J., DARVEY, N. L. AND BARBER, H. N. 1967. Effects of colchicine on meiosis of hexaploid wheat. Nature, 216 , 687-688.

ERICHSEN, A. W., FRANZKE, C. J., SANDERS, M. E. AND ROSS, J. G. 1962. Colchicine-induced mutations in sorghums which affect qualitative characters. J. Hered., 53, 304-308.

FINCH, R. A. AND BENNETT, M. D. 1979. Meiotic stability in control and newly colchicine-induced dihaploid barley. Can. J. Genet. Cytol., 21, 33-35.

FRANCIS, A., JONES, R. N., PARKER, J. S. AND POSSELT, U. K. 1990. Colchicine-induced heritable variation in cell size and chloroplast numbers in leaf mesophyll cells of diploid ryegrass (Lolium perenne L.). Euphytica, 49, 49-55.

HAGUE, L. M. AND JONES, R. N. 1987. Cytogenetics of Lolium perenne. 4. Colchicine induced variation in diploids. Theor. Appl. Genet., 74, 233-241.
HASSAN, L., JONES, R. N. AND POSSELT, U. K. 1989. A novel source of genetic variation in ryegrasses (Lolium multiflorum, $L$. perenne). Heredity, 63, 339-342.

HASSAN, L., JONES, R. N., PARKER, J. S. AND POSSELT, U. K. 1991. Colchicine-induced heritable variation in cell size and chloroplast number in the leaf cells of inbred ryegrasses (Lolium perenne, L. multiflorum). Euphytica, 52, 39-45.

KARP, A. AND JONES, R. N. 1983. Cytogenetics of Lolium perenne. Part 2. Chiasma distribution in inbred lines. Theor. Appl. Genet., 64, 137-145.

LEVAN, A. 1939. The effect of colchicine on meiosis in Allium. Hereditas, 25, 9-26.

LOIDL, J. 1988. The effect of colchicine on synaptonemal complex formation in Allium ursinum. Exp. Cell Res., 178, 93-97.

LOIDL, J. 1989. Colchicine action at meiotic prophase revealed by SC-spreading. Genetica, 78, 195-203.

LOIDL, J. 1990. The initiation of meiotic chromosome pairing: the cytological view. Genome, 33, 759-778.

PUERTAS, M. J., DE I.A PEÑA, A., ESTADES, B. AND MERINO, F. 1984. Early sensitivity to colchicine in developing anthers of rye. Chromosoma, 89, 121-126.

SHEPARD. J., BOOTHROYD, E. R. AND STERN, H. 1974. The effect of colchicine on synapsis and chiasma formation in microsporocytes of Lilium. Chromosoma, 44, 423-437.

SPARROW, A. H. 1942. Colchicine induced univalents in diploid Antirrhinum majus L. Science, 96, 363-364.

THOMAS, J. B. AND KALTSIKES, P. J. 1977. The effect of colchicine on chromosome pairing. Can. J. Genet. Cytol., 19, 231-249. 